\title{
The Molecular Sememe: A Model for Literary Interpretation Price Caldwell
}

In this paper I propose to describe, in brief, a semiotic paradigm which results from the redefinition of the linguistic sign as a molecular sememe. Borrowing a tactic from Wittgenstein, I wish to use the game of chess as an analogy for the sake of describing what a molecular sememe is. Then I hope to use it further to sketch several implications of this semiotic paradigm for literary criticism and critical theory.

The fundamental unit of meaning in language, the sememe, in this view, is not a word, a morpheme, a phoneme, or (even smaller) a "semantic feature". Rather, it is a larger synthetic structure - the small "molecule" of possible counters from which one is chosen at any salient decision-point in the creation of an utterance.

Ludwig Wittgenstein, in the Philosophical Investigations, compared a word to a chess piece. ${ }^{1}$ In doing so he meant to emphasize the word as something used: so do I. But rather than saying a word is a chess piece, I'd rather say that a word is analogous to a "move" in chess. At the same time, meaning does not belong to the word itself, or to the move itself, but to the move in context in an actual game. To put it more precisely: the meaning of any move is created in its contrast to whatever other moves one could have made at that point in the game. This small set of possible moves, itself dictated by the whole previous course of the game, is what I call the "molecule". Meaning, then, belongs to the molecule of possible moves, as it is marked by the particular move one makes.

I call this molecule the "sememe" because it is the unit of meaning. What do we mean by "meaning"? Let's be vague about it for the moment. Whether he can say it or not, any knowledgeable kibitzer at the chess game will understand its meaning. Meaning here is the whole complex of implication for the opponent's next move. In language, the implications of any word chosen at any decision-point in the discourse might be equally difficult to articulate.

\footnotetext{
${ }^{1}$ Ludwig Wittgenstein, Philosophical Investigations, I, G. E. M. Anscombe, Trans., (Oxford: Basil Blackwell, 1953), § 108.
} 
So let's not try to narrow its sense here: an inclusive sense will do, one which includes reference, syntactic value, logical implication, illocutionary force, metaphor, and emotional import.

How does this "molecule" work? Everyone has noticed how, on a clean surface, water will bead up in a coherent droplet. A few specks of dust, when dropped onto the surface, will instantly move as far away from each other as possible. I don't know whether this behavior is a function of electrical charges or surface tension, but the bits of dust will maximize the distances among themselves. So, too, I argue, signs and meanings, whenever they are brought into a local relationship, distinguish themselves from each other as well as they can. I argue that this phenomenon is a fundamental semiotic fact. It underlies the power of contrastive sets and gives meaning to the differential that has been important to structuralist linguistics since Ferdinand de Saussure first proposed it. $^{2}$

I realize that structuralism is now widely considered to have been a failure in predicting linguistic structures, even though the concept of the contrastive meaning has been influential in structuralist criticism, especially in Europe - witness the work of Levi-Strauss, Roland Barthe, Michel Foucault, Julia Kristeva and others. The concept of language as a set of arbitrary and shifting relationships between the "expression plane" and "content plane," on which no individual has any influence, is famous enough not to need elaboration here.

But if this is the case, why did structuralism fail to make the principle of the differential generate all the structures of language? I have tried to answer this more fully elsewhere, ${ }^{3}$ but the short answer is that structuralists following Saussure believed too strongly in the notion of La Langue as in itself the principle of order. For instance, all phonemes were said to have meaning in their difference from all other phonemes; by implication, it was hoped that morphemes too would prove to have meaning by their difference from all other morphemes. In short, Saussure failed to prove his idea of order - not, as Jakobson insisted, because he failed to recognize that morphemes have positive and durable meanings of their own, ${ }^{4}$ but because he looked for it on the wrong scale. He expected his principle of order, the concept of La Langue, to determine individual speech by the operation of a single, large-scale system.

\footnotetext{
${ }^{2}$ Saussure, Ferdinand de, Course in General Linguistics, Wade Baskin, Trans., (New York; McGraw-Hill, 1966).

${ }^{3}$ Price Caldwell, "Molecular Sememics: A Progress Report," Meisei Review (Tokyo, Japan), Vol 4 (1989), 65-86.

${ }^{4}$ Roman Jakobson, Selected Writings, Vol. 1 (The Hague: Mouton, 1971), 66.
} 
Of course we all believe that the fundamental principles, whatever they are, must be universal and large. The Molecular Sememe, however, argues for the principle of a local order operating on a small scale, and within the momentary dynamics of speech rather than in the large structures of Language. The molecular sememe is a small whole, a tiny universe, a momentary order possessing both a differential and a coherence. Furthermore, it is a complex whole, in which highly subtle nuances of difference are to be recognized, but only among a few (typically two or three) foregrounded choices at a time. ${ }^{5}$ Such a structure is consistent with what has been described as the "bottleneck of attention," and could also express the Gestaltisch qualities which have been observed to pattern human perception. If it can also be shown to be a basis on which an ordinary language could be described, it could allow us to make the so-far elusive connections between language and sense-perception, neurology and psychology, and help put the aims of Cognitive Linguistics on a solid footing.

I have spent a lot of time trying to do that. My purpose here, though, is to suggest some implications of this paradigm for literary criticism. Literary creation, as Wittgenstein suggested, is a game-playing activity. In discourse, as in chess, the moves are chronologically ordered, and each move stands in presupposition to all the moves which come after it. In chess, the configuration of the board is available to our inspection at any time; this configuration is a record of all the previous moves which, in their collective and hierarchical presupposition, constitute the context within which the next move, like the next sentence, has its meaning. If we are familiar with the conventions of chess or of discourse, we may be able to know whether we are, say, into the endgame, or which of many familiar gambits has been used. Still, in both chess and discourse, the intentions of the players and their game plans must be inferred.

Now let's take a closer look at what we mean by a "move," and what we mean by the "context" within which that move has meaning. First, "context". In a chess game, context for any next move is quite literally manifested in the present configuration of the board, which is, itself, an expression of all the presuppositions that affect the next move. In chess, you could make a list of these presuppositions, and it would be equivalent to a list of all the previous configurations of the board. The pieces on the board which haven't been moved in a long time,

\footnotetext{
${ }^{5}$ In contrastive sentences, at least. There are other kinds of sentences, and other configurations of molecules.
} 
in effect, stand in "deep presupposition," while the pieces that have been recently moved stand in "immediate presupposition" to the next move. Since the "moves" in chess are not only chronologically ordered, but still recorded in the situation of the board, the "hierarchies of presupposition" ought, in principle, to be discoverable.

Now, what do we mean by a "move"? It consists of two elements: first, the "hierarchy of presupposition" acts to select a set of possible next moves. But before I can make a move, I have to guess the meaning of my opponent's last move. That move is recorded on the board, and that move plus all the previous moves all stand as a hierarchical order of presuppositions, all of which dictate what I can and cannot do next. The set of possible moves dictated by those presuppositions (and informed by my game plan) is called the molecule; the action of all those presuppositions to dictate the alternatives included in this molecule, I call the "Molecule selection structure." Once the molecule is constituted, all that is left is to select one of those possibilities, and thus "execute" the molecule. Thus a "move" is really a "molecule selectionand-execution structure," or what I call an MSES. We can describe text, then, or discourse, as an overlapping order of MSES's in which a molecule executed in one move takes its place in the hierarchy of presupposition which enables the selection of the next molecule.

What are the implications of all this for literary criticism and critical theory?

1. The model suggests a way to clarify the problem of interpretation. The problem is that meaning belongs to the molecule, and not to the word, when we cannot know for certain what other, unstated terms the molecule contains. All we have is the stated term; that term means what it means by contrast to the other terms in the molecule, but we cannot know for certain what they are. It makes a big difference, for example, when we hear the word "strike," whether the molecule is $\{$ strike/ball $\}$ or $\{$ strike/stroke $\}$, or $\{$ strike/go back to work $\}$, or \{strike/retreat\}. The molecule as the writer (or speaker) constructs it represents the writer's (or speaker's) intention. The molecule as the reader (or hearer) reconstructs it represents the reader's interpretation. In both cases, the molecules are selected by a whole hierarchy of presuppositions, not all of which are in the text, and which include the place and time of writing or reading. Thus there is as much good reason in examining the readers' assumptions - as 
reader-response criticism insists - as there is in searching for historical evidence of the writer's intentions.

2. Nevertheless, historical criticism is possible, not impossible. Among some poststructuralists, deconstructionists and reader-response critics, the only conclusion that seems possible is a total relativism in which every effort to read the past is seen as merely an imposition on the past of the categories of the present. This is a consequence of the arbitrariness doctrine of Saussurian structuralism, and a post-structuralist recognition that the slippage between the "expression plane" of language and the "content plane" is total. Molecular Sememics recognizes, however, that the language is not a single system, and that very often the text itself contains, within its hierarchy of MSES's, evidence of every molecule's missing terms.

Or perhaps the information is contained in literary conventions outside the text. I remember being puzzled for a long time by Emily Dickinson's wonderful poem which begins, "I heard a fly buzz when I died." Someone pointed out to me that there was a convention in 19th century novels - Uncle Tom's Cabin is one - of obligatory and beatific death-bed scenes, in which the dying person has an epiphany in which Jesus calls her to heaven. In other words, had Emily Dickinson been evoking the conventional deathbed scene, she would have begun the poem with lines like

I heard the chariots coming when I died

or

I heard the bells a-ringing when I died

or

I heard the angels singing when I died.

And if we think of such lines as these constituting the "molecule" of possible first lines for her poem, then we feel we "know" what she means when we hear her say, "I heard a fly buzz when I died." For the line means what it means by its contrast to those other lines. Of course the process of reconstructing those molecules is partly guesswork and never certain; but it provides a 
method for the effort to place the poem in historical and cultural context, as the "new historicism" has argued.

3. The "death of the author" has been grossly exaggerated. His demise is another post-structuralist conclusion drawn from Saussure's argument that the Language is a monolithic structure which cannot be influenced by any single individual; thus, they say, it is more true that the language "speaks us" than that we speak the language. But the model of the molecular sememe reminds us that language is not a single monolithic structure. Language, as Saussure knew, though his followers forgot, is merely a set of habits and conventions. It is, to be more precise, a conventionalized and compromised collocation of fossilized molecules, capable of enabling anyone to think he can think. And to that extent the post-structuralists are right. But at the level of individual speech, the molecule is dynamic and alive: the creative user of language can make new molecules, or at least mark old ones in different ways, and is not totally at the mercy of the system. Shakespeare, for instance, was good at creating new molecules: that is, he was able to make molecules which had never contained precisely those counters before. And by putting them in dynamic contrast to each other for the first time, he justified Shelley's argument that poets are the "unacknowledged legislators of the world" in that they (sometimes) do actually create the meanings by which we live our lives.

4. "Deconstruction" is a legitimate enterprise, but its implications are sometimes very unfair. What makes deconstruction possible is the recognition that meaning belongs to the molecule as a whole, not solely to the selected term. The critic can therefore "rewrite" the text by deliberately selecting the unmarked terms rather than the marked ones, and legitimately claim to be "deconstructing" the text. The immediate result will sometimes seem to turn the writer's explicit meaning on its head. Does that reveal the true motives the writer was trying to avoid admitting? Sometimes. In fact every term's counter-meanings are always involved in the meaning of the term, and deconstructionist techniques have been a powerful means of illustrating that principle. Among the so-called post-colonialists engaged in cultural criticism, every writer, it seems, is accused of resisting or hiding his "situatedness" in a set of racist, sexist, and classist assumptions. However, it is also true that the writer has as good a chance of knowing what those counter-meanings are as the critic. 
5. Postmodernism's discovery of the "total indeterminacy" of the text is a gross exaggeration. Total indeterminacy would require a total lack of coherence among the molecules of a text. It would be more accurate to say that as a writer, I can decide how much determinacy I will build into the text. I can do that by building greater or lesser degrees of consistency and redundancy in the molecules I construct. If I am writing an essay, I will create a lot of redundancy because I want to achieve clarity of thought; if I am writing a story I may well build in indeterminacy because I want to achieve opacity, a sense of the real as beyond easy reduction. A story fails when its events seem merely illustrations of a thesis, every incident consistent with a single narrative or thematic line.

A critic, on the other hand, surely has, as one of his tasks, to estimate the degree of determinacy the text contains. If there is little, he cannot be confident of a single thematic interpretation. The writer is trying to create a world, not get across an idea. Many of the missing terms of his molecules may be in that world, then, not in the text, and so the story will not have the kind of explicit verbal consistency and redundancy that an essay ought to have.

To illustrate at least some of these points, let me choose a passage, say, a speech by Hamlet:

How all occasions do inform against me,

And spur my dull revenge! What is a man,

If his chief good and market of his time

Be but to sleep and feed?

If we estimate the amount of indeterminacy there is in this speech, I'd say there is quite a lot. But let's look at the obviously interesting words: "inform," "spur," "chief good and market," "sleep and feed." Is it possible to reconstruct the molecules these terms mark?

One way to do this is to imagine a molecule-selection structure such as

How all occasions do against me 
and try to guess what words could fill the molecule defined there. With no knowledge of the selected word I'd probably guess words such as "tell" or "press in," or "work." These terms are unlikely to have ever existed in the same molecule before. In fact, the term chosen could link several wholly different molecules, such as $\{$ inform/tell $\}$ and $\{$ inform/impress $\}$ and $\{$ exert pressure/work $\}$. Thus the richness of significant ambiguity is created by Shakespeare's using a complex molecular structure: as a result, the single word "informs" also evokes all the others as unmarked potentials. Thus, it means something like to "tell on" or to "slander" or to "put pressure on" and "to influence," all at the same time.

By a similar process, we can see how the molecular structure makes "market" mean "use" and "service" and "value" at the same time. The word "market" suggests a molecule of economics terms in which words like "goods and services" exist, items which can be traded for the wherewithal to "sleep and feed." Thus "market" also suggests, in varying molecular relations, words like "services" or "value."

In short, I submit that the Molecular Sememics paradigm can help explain how new meanings are created by special and controlled contexts. The molecular principle means that local options are available at every turn, and we are NOT in fact limited to the determination of some monolithic notion of The Language.

To put it another way, Molecular Sememics argues that creativity is indeed possible. Creativity of the most profound kind occurs even in the most immediate and local inventions of ordinary people in everyday speech. 